\section{Groundwater in geologic processes}

\section{By Steven E. Ingebritsen \& Ward E. Sanford}

Cambridge University Press, 1998. Hardback, £45.00/US\$69.95. ISBN 052149608 X.

Contrary to usual groundwater textbooks which dwell on fields such as water supply, pollutant remediation, or oil recovery, this book centers around the role of groundwater in more fundamental geological processes such as sedimentary basin evolution, diagenesis, ore deposition, and tectonism. A coherent and comprehensive introduction into these phenomena is presented. The major difficulty in this context is that - as the book states - "everything is coupled". So emphasis is put on phenomena which exhibit the coupling of groundwater flow with heat transport and deformation, as well as solute transport and geochemistry.

The book actually consists of three parts: In the first three chapters the basics of groundwater flow, solute and heat transport are compiled. In the following chapters one after the other the basic geological subjects are presented in which groundwater plays a role. These include regional-scale flow and transport systems, ore deposits, hydrocarbons, geothermal processes, earthquakes, evaporites, diagenesis and metamorphism. This part is basically drawing on the results of a number of case studies dealing with the respective subjects, not few of them from the authors' own work. The third part of the book is made up of the problem sections, which follow after every chapter.

The approach assumes that the reader is familiar with concepts such as phonons, entropy, etc. So while on one hand the text is introductory, on the other it is only easily accessible to the advanced student and scientist. An attractive feature of the second part is the injection of ball-park figures and order of magnitude computations, which are sometimes carried out. It would have been desirable to have such computations more often. This would also have made the first three chapters much more important for the following chapters. As they stand now, they are quite detached from the rest of the book. In fact, the second part can be read separately.

The problems provided present further opportunity to practice back of the envelope computations. They are a real asset of the book and in a future edition, it might be of interest to add an appendix with the solutions for the interested students.

In coupled phenomena crude estimates must be followed by a more rigorous treatment. The means for treating the problems fully i.e. coupled numerical models as well as their weaknesses are not discussed adequately in this text although they are the basis of most of the case studies presented. Up to today the modeling of coupled processes is a major and often unresolved challenge. Some words of caution concerning the quantitative approach would have been appropriate. For the megascale of part 2, the micro- and mesoscopic laws of the introductory chapters are not necessarily adequate. Natural media are heterogeneous on many scales. Going to the large scale requires an upscaling procedure which for many processes is unsolved - and if large singular structural or chemical features are not well known - may even be impossible to solve. Just using local parameter values as obtained from cores and water samples may not even give the correct order of magnitude for the large scale. So where to get the data for serious calculations from? Even for the simplest case of constant density flow, large scale parameters are rather fitted in an inverse modelling approach than predicted from local measurements. Coupled phenomena are usually non-linear and to make sure a solution is correct is not trivial. As a minimum requirement grid convergence of a calculation should be checked. It is still rarely done and editors of earth science journals should insist on it before publishing a paper. Similarly, no computation is complete without an extensive sensitivity analysis given the fact that with critical phenomena involved, modes of flow and transport may change drastically with the choice of parameters. Convective phenomena are intrinsically three dimensional, still for computational reasons often vertically 2D approximations are used. Non-linear 3D problems are up to today a challenge for super computers as are multi-species, multiphase problems. So what do the computational examples really present? They are still not more than crude prototypes which allow interpretative and narrative process understanding rather than any quantitative reliability or predictive power. They are the modern back of the envelope calculation providing plausibility arguments in hypothesis testing. In this context I do not envy the designers of nuclear waste repositories for the expectations their clients usually have. A lot of humility is required when dealing with large scale, long term phenomena quantitatively. This is definitely the biggest difference when talking about groundwater in geological phenomena as opposed to shallow groundwater in water supply.

Still, the book serves its purpose well. It closes a gap in groundwater textbooks and can be recommended for the advanced student and researcher. On the whole these readers can obtain an overview in an easy-to-read manner. To dig deeper they have to address the special literature which abounds for each of the themes and to which the rich reference list allows a fast access. And of course they will be happy to find out that a lot is still to be done in this field.

\section{Woffgang Kinzelbach}

Swiss Federal Institute of Technology Institute of Hydromechanics and Water Resources Management

HIL G 37.3

ETH-Zuerich

CH-8093 Zuerich-Hoenggerberg

SWITZERLAND

Tel: +41-1-633 3066

Fax: +41-1-6331061

E-mail: kinzelbach@ihw.baug.ethz.ch

\section{Ore-microscopic and geochemical studies of primary (hydrothermal \& pegmatitic) uranium minerals}

\section{By S.S. Augustithis}

\section{Rainbow-Theophrastus Publishing} Group, Athens-Greece/Calcutta-India, 2000. 81 pp., with 168 figures on 70 plates, hardback. ISBN 81-901072-0-8.

Uranium plays a great role in the life support of mankind. Its widespread use in various spheres undoubtedly exerts a profound effect on the development of our civilization. Uranium is most widely used in power engineering. Despite conflicting perceptions of nuclear energy, it has good chances for expansion in the future. Supplying nuclear fuel for power plants is one of the important missions of geologists in the immediate future. Because of this, all studies pertinent to uranium deposits and the composition of uranium ores and minerals are subjects of much interest. The reviewed monograph is not an exception.

The author worked in the sphere of ore microscopy under the supervision of prominent mineralogists, such as P. Ramdohr and A. Schuller, while the results of his studies were discussed with notable scientists ( $\mathrm{F}$. Leutwein, A. Schroeder). This allowed the author to investigate uranium minerals from many deposits all over the world, including currently inaccessible or poorly known deposits. This material together with published data was systematized in the sections and appendices related to the principal problems of uranium mineralogy.

The work is plentifully illustrated: microphotographs and analytical results are equal in volume to the text and allows us to attribute this work to atlases that are supplementary to a series of atlases already published by the author. However, it is rather strange that the author excluded from consideration numerous hydrothermal deposits in granites and volcanic rocks, which have 
great commercial importance and scientific interest. This exclusion is in some disparity with the monograph title.

Mineral compositions, contents of minor elements, and uranium isotopes are widely examined in this book, and problems of crystalline structure of uranium oxides and their synthesis are considered.

Description of hydrothermal paragenetic assemblages of uranium oxides is of much interest. The reader can find here a discussion of the general concept of paragenetic assemblages, i.e., a problem that is of great significance for genetic mineralogy but is rarely examined in the literature. Numerous examples of paragenetic assemblages with minerals containing main ore elements $(\mathrm{Pb}$, $\mathrm{Bi}$, As, etc.) are given. Mechanisms of formation of crystalline and colloform $\mathrm{UO}_{2}$ varieties and metamictization of uranium-containing and uranium minerals are considered.

Interesting material is given for the description of pegmatite mineral assemblages. Although pegmatite deposits commonly have no commercial importance, their mineralogy allows investigation of uranium geochemistry under high-temperature conditions.

The section describing alteration of primary uranium minerals is very intriguing. Autooxidation related to the decay of uranium nuclides and the disintegration of crystal lattices, as well as the superposition of products of later hydrothermal solutions, are interpreted as endogenic processes. The supergenic alteration occurs in the presence of oxygen and is pronounced in oxidation zones and weathered rocks. Selective leaching of elements from uranium-containing and uranium minerals and the various mobilities of these elements in different processes are emphasized. These processes are being studied in detail, because uranium ores are considered as natural analogs of radioactive waste repositories. Better knowledge of the processes occurring in these ores may help in the long-term evaluation of the safety of nuclear waste disposal systems.

We would like to make a general remark. The list of references contains merely works published before 1963, although the author points out that numerous works on this subject have come out since then. There are several important and relevant Russian publications which should have been mentioned. Many of them are devoted to the composition and structure of uranium minerals (Sidorenko, 1978; Laverov et al., 1989), the textures and mineral assemblages of uranium ores (Dymkov, 1973, 1985; Petrov, 1977), and the structures and composition of oxidation zones of uranium deposits (Belova, 1975). Moreover, all data on uranium deposits of the former Soviet Union are now non-confidential and may be obtained from archives of various research institutes, including IGEM.

We think that these materials should be mentioned and reviewed in the monograph, together with the most important works in other languages. The uranium deposits in granites and volcanic rocks should be included into the consideration of mineral assemblages, because they are also extremely interesting with respect to mineralogy, geochemistry, and ore genesis. These remarks should be appreciated in the second edition of the monograph (we hope it will appear soon).

This issue is interesting for geologists and anybody who wishes to improve their knowledge of ores and minerals of this important, enigmatic, and often mentioned element.

\section{References (in Russian)}

Belova, L.N., 1975. The oxidation zones of hydrothermal uranium deposits. Moscow: "Nedra" Publ., 180 p.

Dymkov, Yu.M., 1973. The nature of uranium pitch ore. The questions of genetic mineralogy. Moscow: "Atomizdat" Publ., 240 p.

Dymkov, Yu. M., 1985. The paragenesis of uranium-bearing veins. Moscow: "Nedra" Publ., 207 p.

Laverov, N.P., Shumilin, M.V., Mel'nikov, I.V., Luchina, I.A., 1989. Geologyst's handbook on searching and exploring the uranium deposits. Moscow: "Nedra" Publ., 348 p.

Petrov, R.P. (ed.), 1977. Textures and structures of endogenous deposits uranium ores. Moscow: “Atomizdat" Publ., 208 p.+128 ill.

Sidorenko, G.A., 1978. The crystallochemistry of uranium minerals. Moscow: "Atomizdat" Publ., 216 p.

\section{Dr. Anatolii V. Timofeev}

Academician D. Shcherbakov's Laboratoty of Radiogeology,

Institute of Geology of Ore Deposits,

Petrography, Mineralogy, and

Geochemistry (IGEM),

Russian Academy of Sciences, Moscow, RUSSIA

\section{Principles of seismology}

\section{by Agustin Udias}

Cambridge University Press, 2000.

ISBN 0521624789 (paperback),

US\$39.95/GBP 24.95; ISBN

0521624347 (hardback), US\$90.00/

GBP 60.00

A new textbook for general introduction to seismology, "Principles of Seismology" written by Prof. Agustin Udias, has been recently published. It is based on his 25 years' teaching experience at the universities of Madrid and Barcelona. This textbook covers most of fundamental topics in seismology such as seismic wave propagation, ray theory, body and surface waves, focal mechanisms, source models and seismotectonics. It is designed for advanced undergraduates and graduate students.
The most remarkable differences of this textbook from others written for general introduction to seismology lie in its emphasis on fundamental concepts in seismology and detailed mathematical developments for simple and fundamental problems in seismology such as those for one-dimensional cases and for liquid media. Following the complete mathematical developments for these problems is helpful for readers to understand the basic concepts in seismology. As is written in the first page of the textbook, this is "studentfriendly" text designed as an introduction to seismology.

After the introduction chapter, readers are reminded about the basic theory of elasticity. After that, the equation of motion in elastic media and their solutions are derived. After brief explanations of normal mode theory for simple cases, the successive four chapters describe the basic behaviors of seismic waves (reflection, refraction, and ray theory). These chapters are very good for readers to understand the basic ideas.

In the next chapter, travel times of various seismic waves propagating in the Earth's interior and the structures of the Earth are discussed. Due to the character of this book designed as an introductory text intended for advanced undergraduates and graduate students, and possibly due to the limitation of the volume of the text, the explanations on methods and procedures how observed seismological data are employed to construct seismological Earth models are not sufficient. For example, both body waves and normal modes data were used to construct global earth models such as PREM (Dziewonski and Gilbert 1981), in which physical dispersion was used to reconcile two data sets. Explanations on this point are not sufficient. Also, recent studies on the Earth's structures are missing in this text. The author provided readers with books and papers in the references so that readers can learn more advanced subjects and recent topics in studies on the Earth structures.

The following five chapters cover surface waves, wave propagation, wave dispersion, free oscillations, anelasticity and anisotropy. The basic mathematical developments for surface waves and wave dispersion are good for readers to follow in order to grasp fundamental concepts on these subjects. Since other subjects are not fully developed in the text, readers should refer to other textbooks suggested by the author for advanced studies. Also, the explanations on methods and results of interpretation of surface waves and free oscillation data to determine the Earth structures are not sufficient, although some observations are included in the text.

In the next chapter, brief explanations on focal parameters of earthquakes are presented. More detailed explanations on this subject seem to be desirable, since this subject is very basic in seismology, and since this text is written for "beginners" in seismology. The following two chapters cover topics 
such as equivalent body forces, double couples, seismic moment tensor, and so on. Following the mathematical developments in the text is helpful for readers to understand these basic concepts. Brief explanations on "models of fracture" are followed.

Methods of determination of source mechanisms are covered in the next chapter. I think that more detailed explanations for various methods should be included for this subject. For example, determination of source mechanisms using polarity data of body waves is one of the most fundamental analyses in seismology and should be covered in more detailed manners for "beginners" in seismology. Also, moment tensor (or centroid moment tensor) solutions are routinely determined by various institutions nowadays, and more explanations on this point are desirable, although this topic is mentioned briefly.

In the next chapter, seismicity, seismotectonics, and seismic risks are covered briefly. Since these topics are related to various disciplines of science and technology in wide ranges, it is likely to be difficult to provide sufficient explanations within a limited space. Readers should read some other textbooks suggested by the author. The final chapter covers the topics of seismographs.

There is one important subject missing in this textbook unfortunately. That is methods of inversion of observed seismological data. Seismology is an observational science, and techniques to interpret observed data are very important component parts of seismology. Although it will be difficult to provide detailed explanations on this subject due to the limitation of the volume of the text, explanations on basic concepts will be highly useful for "beginners" in seismology.

In summary, "Principles of Seismology" is a good introductory text to seismology for advanced undergraduates and graduate students. Readers can understand fundamental concepts in seismology by following the mathematical developments for simple cases presented in the text. This textbook will be a good introduction to more advanced textbooks, as the author hoped in the preface.

\section{Tatsuhiko Hara}

International Institute of Seismology and Earthquake Engineering

Building Research Institute

1 Tatehara, Tsukuba

Ibaraki, 305-0802

JAPAN

Tel: $+81-298-64-6644$

Fax: +81-298-64-6777

E-mail: thara@kenken.go.jp

\section{Looking into the Earth: An introduction to geological geophysics}

\author{
By Alan E. Mussett and M. Aftab \\ Khan
}

Cambridge University Press, 2000.

475pp. ISBN 0-521-78574-X

(paperback),US\$42.95; ISBN 0-521-

78574-3 (hardback), US\$110.00.

This book is aimed primarily at introductory and intermediate university and college students taking courses in geology, earth science, environmental science and engineering. Geophysics, the application of physics to the study of the Earth from its surface to its center, is an essential part of modern earth science. Modern ideas of the structure and evolution of the Earth, the search for oil, water and minerals, and detailed studies of the near-surface, are based extensively on discoveries made using geophysics.

It is the physical properties of rocks and their spatial variation that the geophysicist measures remotely, usually at the Earth's surface. Geophysics describes the subsurface in physical terms, not in terms of composition, minerals, grain-sizes, and so on, which are familiar to the geologists. Because geologists are often unfamiliar with physics (and associated mathematics), there is a tendency either to ignore geophysics or to accept what a geophysicist says without understanding the qualifications. All subjects have their assumptions, often unstated but known to practitioners. There are reservations and limitations on what geophysics can tell us, which need to be understood. So earth scientists, including practising geologists, environmental scientists, field archaeologists and civil engineers, who may call on the services of a geophysicist, need necessary knowledge of the principles and applications of geophysics.

Looking into the Earth is an introduction to geophysics suitable for those who do not necessarily intend to become professional geophysicists. Unlike other books that deal with either "global" or "exploration" geophysics, This book is primarily concerned with the geological applications of geophysics (i.e. geological geophysics), but also with some "pure" geophysics necessary for the student to understand, such as the interior of the Earth and its geomagnetic field. The book is organized into two parts: Part I describes geophysical methods; and Part II illustrates their use in a number of extended case histories. In Part I, Subpart 1.1 "Data Acquisition and Processing" first gives the concept of geophysical measurements, data reduction and interpretation, and then describes the general principles about Fourier analysis and digital filtering. Methods that have many of their physical princi- ple in common are then grouped into subparts. Within the sub-parts, each is given a chapter after a beginning chapter on the physical principles needed to understand these geophysical methods. There are subpart seismology, gravity, magnetism, electricity, radioactivity, geothermics and subsurface geophysics - a successful overview of the whole field of solid earth geophysics from the smallest to the global scale.

Part II describes a number of applications of geophysics, including case studies. It begins with an introductory section describing how appropriate geophysical methods are chosen. The following chapters describe a number of case studies: globe tectonics, the East African Rift system, hydrocarbon exploration, exploration for metalliferous ores, volcanoes, craters and K/T mass extinction, hydrogeology and contaminated land, location of cavities and voids, and archaeological site surveying. This part is the most impressive of this book, which not only illustrates to students who are unfamiliar with geophysics what kinds of information geophysics can offer and their limitations, but also provides outstanding examples of geophysical applications to the much wider circle of readers who are working on these fields.

The authors recognize that many students taking introductory courses in geophysics are not necessarily fluent in mathematics or physics, so mathematical principles are introduced at an elementary level. Throughout, the emphasis is on what geological (or archaeological or civil engineering) information geophysical methods can yield.

The authors have taught geophysics at universities for more than 30 years, and are author (or co-author) of textbooks on geology and geophysics. Student problems, exercises and further reading suggestions are included at the end of many chapters, and the important terms students should understand are shown in bold type.

Looking into the Earth provides a successful overview of the whole field of solid earth geophysics. The treatment of this broad subject is thorough, but it is clearly written and does not get bogged down in details and mathematics. The material is presented at a level accessible to the geology student with a limited physics and mathematics background, and gives the best coverage of geophysical case studies published to date. The illustrations are excellent. It is a well-written textbook for undergraduates in the Earth Sciences. Moreover, it contains a wealth of information and comment, and will unquestionably prove of value and interest to a much wider readership.

It is an excellent textbook which deserves the highest recommendation.

\section{Prof. Xuanzhi Wu}

Institute of Mineral Resources

Chinese Academy of Geological Sciences 26 Baiwanzhuang Road, 100037, Beijing CHINA 